\title{
Megalopenis in an infant with VACTERL association
}

\author{
U B Nelumdeniya ${ }^{1}$, KHI Srimathi ${ }^{2}$, P S De Silva ${ }^{3}$
}

Sri Lanka Journal of Paediatrics, 2007; 36: 118-119

(Key words: Megalopenis, infant, VACTERL association)

Complete spectrum of VACTERL association comprises vertebral anomalies, anal atresia, congenital cardiac defects, oesophageal atresia, renal dysplasia and limb anomalies ${ }^{1}$. Prune-belly syndrome is characterized by the triad of deficiency of the anterior abdominal wall muscles, dilatation of urinary tract and cryptorchidism ${ }^{2}$. Three cases of concordance of VACTERL association and prunebelly syndrome have been reported ${ }^{3,4,5}$. We report a case of VACTERL association who also has megalopenis and most of the features of prunebelly syndrome.

\section{Case Report}

A 4-month-old infant was referred from a surgical unit for the evaluation of a febrile illness. He was the first child of non-consanguineous parents. There was oligohydroamnios antenatally and the child was born at 38 weeks of gestation by elective caesarean section due to transverse lie. The fetal movements had been normal.

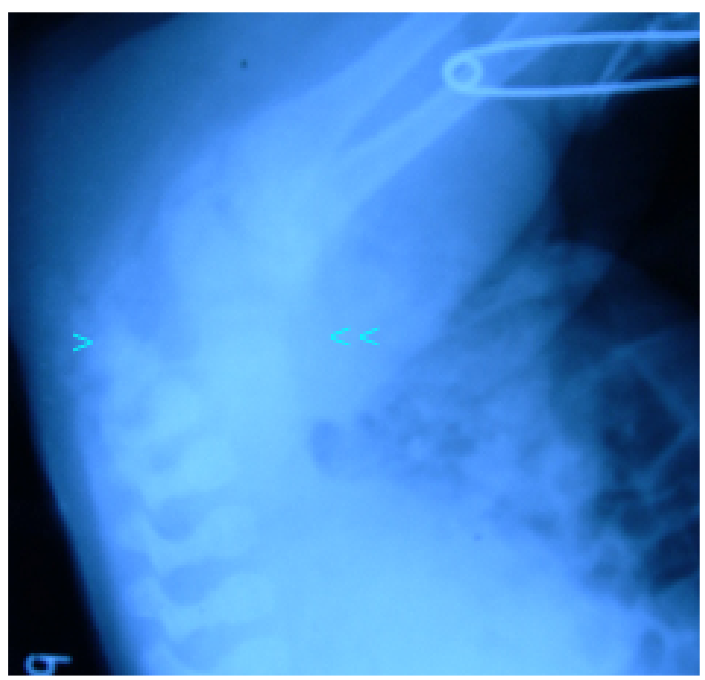

Figure 1 Sacral agenesis $(>)$, absent gas in distal large bowel $(<<)$

\footnotetext{
${ }^{1}$ Senior Registrar in Paediatrics, ${ }^{2}$ Registrar in Paediatrics, ${ }^{3}$ Consultant Paediatrician, Lady Ridgeway Hospital for Children, Colombo
}

(Received on 11 January 2007. Accepted on 10 February 2007)
Soon after birth, a high imperforate anus was detected (figure 1) and sigmoid colostomy was done on the second day of life. Furthermore, distal loopogram showed recto-vesical fistula (Figure 2).

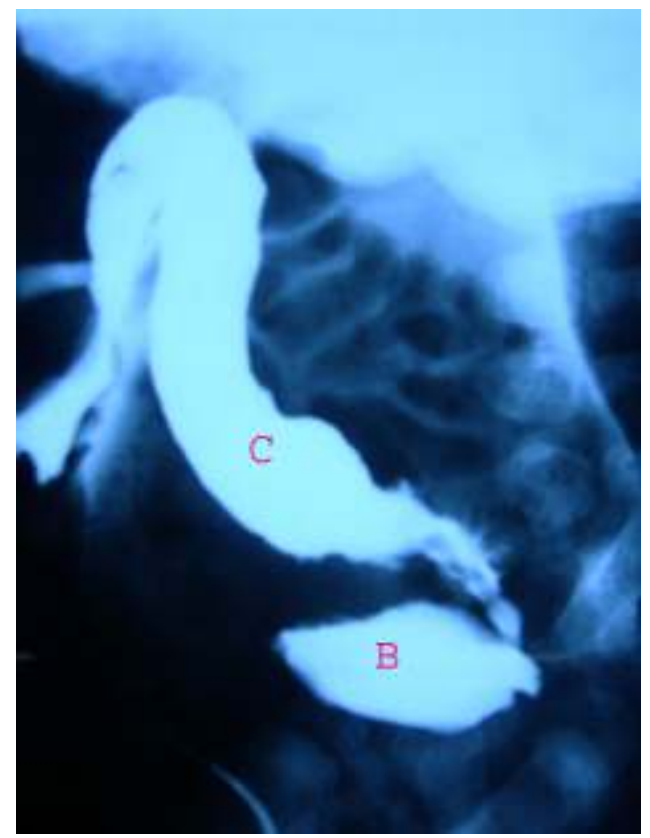

Figure 2 Distal loopogram showing rectovesical fistula. Colon(C), Bladder (B)

Further investigations revealed that the patient had sacral agenesis, ostium secundum atrial septal defect, patent ductus arteriosus and a small hydronephrotic left kidney with poor corticomedullary demarcation. The bladder wall was thickened and ureters were not dilated. This patient did not have tracheo-oesophageal fistula. On the basis of above findings a diagnosis of VACTERL association was made.

The most striking feature of this child was his large phallus (megalopenis). It was $7.5 \mathrm{~cm}$ in length and the overlying skin of the penis had rugosities (figure 3,4). There was bilateral cryptorchidism. Investigations revealed that both testicles were in the inguinal canals, penis was hypertrophied and urethra was dilated (megalourethra). The anterior abdominal wall was lax though deficiency of the abdominal musculature could not be reliably excluded. These findings suggested an incomplete prune-belly syndrome. 

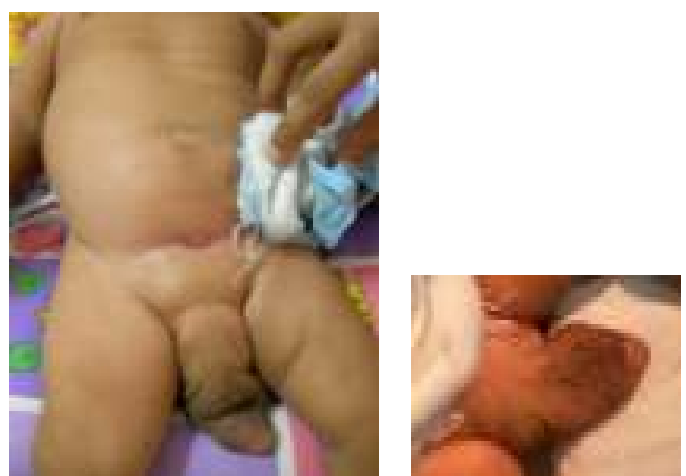

Figure 3 \& 4 Megalopenis with overlying skin rugosities

\section{Discussion}

Associations such as VACTERL are caused by nonspecific developmental disruption acting on developmental field (embryo) in early first trimester ${ }^{6}$. A disruption in differentiating mesoderm in first 4-5 weeks has been suggested to be the basis for VACTERL association. Hence, other mesodermal structural defects are occasionally found with VACTERL association ${ }^{7}$. Urogenital anomalies like unilateral or bilateral cryptorchidism, hypospadius and micropenis in males and ambiguous genitalia and bladder exostrophy in females have been frequently described in VACTERL association ${ }^{8,9}$. In the largest such series of 286 patients, 81 (28\%) had severe genital defects ${ }^{7}$. Abdominal wall abnormalities like omphalocele and gastroschisis are also occasionally reported.

As far as we know our case is the second reported case of megalopenis associated with VACTERL association. First case was reported in India by Shah D et $\mathrm{al}^{4}$. In this case, complete form of prunebelly syndrome concordance with VACTERL association was seen. The patient had megalopenis with rugosities of the overlying skin as in our case.

Lukusa, et $a l^{5}$. described incomplete prune belly anomaly in a female child with additional features of the VACTERL association. Ozturk, et $a l^{3}$ for the first time reported concordance of complete prune belly syndrome and VACTERL association in a premature male child. Our case had bilateral cryptorchidism, lax abdominal wall and megalourethra. These features would suggest the additional diagnosis of prune-belly syndrome. Early disturbance of mesodermal development in both the abdominal wall and the urinary tract have also been suggested to be responsible for prune belly syndrome ${ }^{10}$. This should explain why VACTERL association and prune-belly syndrome sometimes occur in concordance.

\section{References}

1. Czeizel A, Lundanyl I. VACTERL-association. Acta Morphol Hung 1983; 32: 75-96.

2. Jennings RW. Prune belly syndrome. Semin Pediatr Surg 2000: 9: 115-20.

3. Ozturk B, Weber HP, Ganz A. Concordance of prune belly syndrome and VACTERL association. Klin Padiatr 1994; 206: 406-9.

4. Shah D, Sharma S, Faridi M M, Mishra K. VACTERL association with Prune-Belly syndrome. Indian Pediatr 2004; 41(8): 845-7.

5. Lukusa T, Moerman P, Fryns JP. Caudal developmental field defect with female pseudohermaphroditism and VACTERL anomalies. Genet Couns 1996; 7: 207- 12.

6. Martinez-Frias ML, Frias JL. Primary developmental field. III: Clinical and epidemiological study of blastogenetic anomalies and their relationship to different MCA patterns. Am J Med Genet 1997; 70:115.

7. Botto LD, Khoury MJ, Mastroiacovo P, Castilla EE, Moore CA, Skjaerven R, et al. The spectrum of congenital anomalies of the VATER association: An international study. Am J Med Genet 1997; 71: 8-15.

8. Weaver DO, Mapstone CL, Yu P. The VATER association: Analysis of 46 patients. Am J Dis Child 1986; 140: 225-9.

9. Kiran PSS, Dutta S, Narang A, Mukhopadhyay K. Unusual manifestations of VACTERL association. Indian Pediatr 2003; 40: $162-5$.

10. Walker J, Prokurat AI, Irving IM. Prune belly syndrome associated with exomphalos and anorectal agenesis. J Pediatr Surg 1987; 22: 215-7. 
